\title{
Redo off-pump coronary artery bypass grafting via a left thoracotomy
}

\author{
Ibrahim Duvan, Sanser Ates, Burak Emre Onuk, Umit Pinar Sungar, Murat Kurtoglu, Yahya Halidun Karagoz
}

\begin{abstract}
Background: In this study, we retrospectively reviewed our experience in a meticulously selected group of patients undergoing redo off-pump coronary artery bypass graft (CABG) surgery from the descending aorta to the circumflex artery $(\mathrm{Cx})$ and its branches.

Methods: Between January 2001 and October 2013, 32 patients at our hospital underwent redo off-pump CABG from the descending aorta to the $\mathrm{Cx}$ and its branches via a left posterolateral thoracotomy. Of these patients, 27 were male $(84.3 \%)$ and five were female $(15.7 \%)$, with a mean age of $61.66 \pm 8.63$ years. All patients had a patent left internal thoracic artery-to-left anterior descending coronary artery (LITA-LAD) anastomosis. Thoracotomy was performed through the fifth intercostal space. The saphenous vein or radial artery was prepared as a graft at the same time as the left posterolateral thoracotomy from the contralateral extremity, without any positional problem.

Results: The main reasons for surgery in this group of patients were new lesion formation in 19, graft occlusion in six, and both in seven patients. The average operating time was 143.90 \pm 36.93 minutes, respiratory assist time was $5.08 \pm 1.88$ hours, intensive care unit (ICU) stay was $21.3 \pm 4.41$ hours and hospital stay was $5.06 \pm 2.74$ days. Thirty-eight bypasses were performed. The follow-up period was $56.17 \pm 39.2$ months. Six patients were lost in the follow-up period and four patients died. Twenty-two were alive and free of cardiac problems.

Conclusion: Redo off-pump CABG via a left posterolateral thoracotomy provided a safe and effective surgical approach with lower rates of postoperative morbidity and mortality in patients who required revascularisation of the $\mathrm{Cx}$ and its branches.
\end{abstract}

Keywords: coronary artery bypass grafting, re-operation, circumflex artery, thoracotomy

Submitted 10/12/13, accepted 20/10/14

Published online 2/12/14

Cardiovasc J Afr 2015; 26: 25-28

www.cvja.co.za

DOI: $10.5830 / \mathrm{CVJA}-2014-064$

Department of Cardiac Surgery, Guven Hospital, Ankara, Turkey

Ibrahim Duvan, MD, ibrahimduvan@ hotmail.com

Sanser Ates, MD

Burak Emre Onuk, MD

Umit Pinar Sungar, MD

Murat Kurtoglu, MD

Yahya Halidun Karagoz, MD
Re-operative coronary artery bypass graft (CABG) surgery is more complicated than the initial $\mathrm{CABG}$ and it may also be more hazardous because of risk factors related to median resternotomy, such as cardiac injury and damage to the patent grafts due to sternal adhesion. ${ }^{1}$ Deciding on the appropriate treatment for recurrent coronary artery disease (CAD), especially conditions such as non-left anterior descending coronary artery (LAD) ischaemic lesions during the existence of patent left internal thoracic artery-to-left anterior descending coronary artery (LITA-LAD) anastomosis is a dilemma. ${ }^{2}$

If the patient is unresponsive to medical therapy, and percutaneous transluminal coronary angioplasty (PTCA) and/ or stenting is not appropriate for revascularisation, alternative surgical strategies, excluding resternotomy and cardiopulmonary bypass (CPB), may be the most appropriate way of revascularising the branches of the circumflex artery $(\mathrm{Cx})$ or right coronary arteries (RCA) (non-LAD territories)..$^{3-5}$ In selected patients, off-pump redo $\mathrm{CABG}$ for the branches of the $\mathrm{Cx}$ via a posterolateral thoracotomy may reduce the risks due to median resternotomy and dissection of the heart.

This procedure to avoid resternotomy and $\mathrm{CPB}$ has become an established and popular way of revascularising recurrent coronary artery disease in the lateral aspect of the heart. In this article, we share our experience of 32 patients who underwent redo $\mathrm{CABG}$ for the $\mathrm{Cx}$ and its branches via a left posterolateral thoracotomy.

\section{Methods}

Between January 2001 and October 2013, 32 off-pump CABG re-operations via a posterolateral thoracotomy for the branches of the Cx system were performed at the Department of Cardiac Surgery of Guven Hospital in Ankara, Turkey. During this time, 450 patients underwent isolated redo off-pump CABG and our study group constituted $7.1 \%$ of this population. There were 27 men and five women, aged $61.66 \pm 8.63$ years, with a mean of 40-76 years (Table 1 ).

Co-morbidity factors of the patients were pre-operative hyperlipidaemia, family history, smoking, hypertension, diabetes mellitus, chronic obstructive pulmonary disease and cerebrovascular disease. The period between the first and redo operation via thoracotomy was $103.03 \pm 63.33$ months (20-264). Only one patient was operated on three times, the others were operated on twice. There were $2.16 \pm 1.019$ anastomoses performed in each of the previous operations and the total number of anastomoses was 67, whereas the number of patent anastomoses was 44. All of the LITA-to-LAD anastomoses were patent and 10 of the RCA and two of the Cx system anastomoses were also patent.

Patients had symptoms of angina, depending on a problem in the $\mathrm{Cx}$ system, and unfortunately medical therapy was unsuccessful. Six had already been revascularised by both PTCA 


\begin{tabular}{|lc|}
\multicolumn{2}{|c|}{ Table 1. Pre-operative demographic data } \\
\hline Variables & Demographic data $(\mathrm{n}=32)$ \\
Age (years) (mean) & $61.66 \pm 8.63(40-76)$ \\
Male, $n(\%)$ & $27(84.4)$ \\
Female, $n(\%)$ & $5(15.6)$ \\
Hypertension, $n(\%)$ & $21(65.6)$ \\
Smoking, $n(\%)$ & $21(65.6)$ \\
Diabetes mellitus, $n(\%)$ & $13(40.6)$ \\
Family history, $n(\%)$ & $22(68.7)$ \\
Hyperlipidaemia, $n(\%)$ & $22(68.7)$ \\
Myocardial infarction, $n(\%)$ & $11(34.3)$ \\
COPD, $n(\%)$ & $6(18.7)$ \\
CVA, $n(\%)$ & $2(6.2)$ \\
COPD, chronic obstructive pulmonary disease; CVA, cerebrovascular \\
accident.
\end{tabular}

and stent. PTCA only was performed in four of the patients. Complete revascularisation is the first priority universally for all patients in cardiac surgery, so these were all candidates for redo CABG. The reason for ischaemic symptoms in six of our patients was graft occlusion, new lesions in 19 , and both in seven (Table 2). New lesions occurred in the left main coronary arteries of eight patients (Fig. 1), and in the rest, in branches of the Cx.

We decided to perform an off-pump posterolateral thoracotomy for redo $\mathrm{CABG}$ in these patients because of the presence of patent grafts (Fig. 2), to avoid the risks of resternotomy, and to access the posterior region of the heart more easily while revascularising the branches of the $\mathrm{Cx}$ system. One of the most significant independent predictors of morbidity and mortality after redo $\mathrm{CABG}$ is reported to be long duration of $\mathrm{CPB} .{ }^{6}$ We therefore decided to avoid $\mathrm{CPB}$ and chose the off-pump redo CABG technique via a thoracotomy for revascularising the lateral aspect of the heart.

All patients underwent redo off-pump CABG via a left posterolateral thoracotomy (Fig. 3) with general anaesthesia after insertion of a double-lumen endotracheal tube. The patient was positioned in the right lateral decubitus position with the pelvis externally rotated slightly to allow access to the femoral

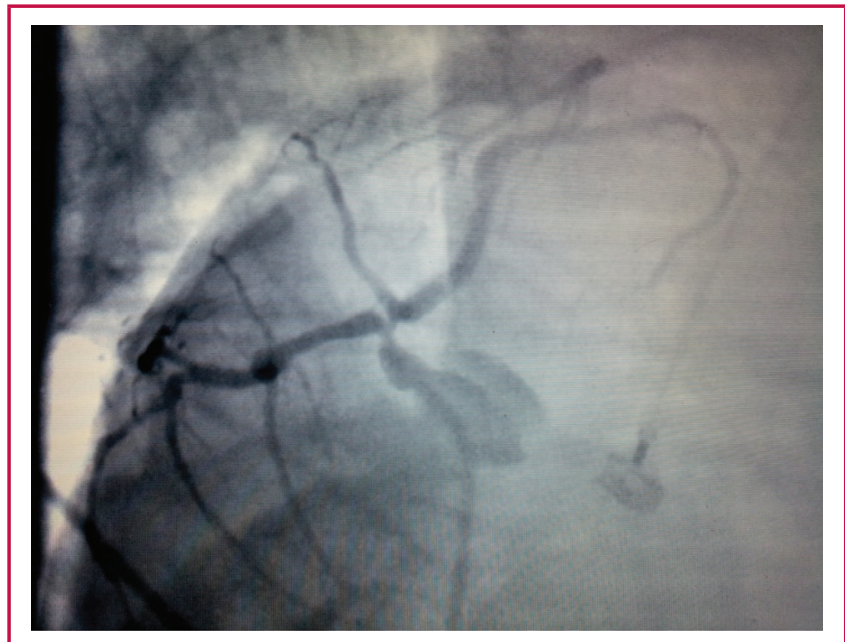

Fig. 1. New lesion in the left main coronary artery of a patient with a patent LITA-LAD anastomosis.

\begin{tabular}{l}
$\begin{array}{l}\text { Table 2. Information on the patients after the first operation up } \\
\text { to the redo Cx CABG via thoracotomy }\end{array}$ \\
$\begin{array}{|lc|}\text { Variable } & \text { Number } \pm S D \\
\text { Number of previous grafts } & 2.1667 \pm 1.019 \\
\text { Patent anastomoses } & \\
\text { LIMA-LAD } & 32 \\
\text { RCA } & 10 \\
\text { Cx } & 2 \\
\text { Reason of redo Cx CABG } & 6 \\
\text { Graft occlusion } & 19 \\
\text { New lesion } & 7 \\
\text { Both } & \\
\text { Interventions } & 4 \\
\text { PTCA } & 6 \\
\text { PTCA + stent } & 103.03 \pm 63.33 \\
\text { Period between the first and redo CABG } \\
\text { via thoracotomy operation (months) }\end{array}$ \\
\hline
\end{tabular}

vessels for cannulating the patient if necessary. The saphenous veins (SV) or radial arteries (RA) were prepared as grafts at the same time as the thoracotomy, from the contralateral extremity, without any positional problems. A supine position before thoracotomy was necessary in only one patient for harvesting the SV because the right SV had been harvested before. In six patients, the SV was harvested and in the rest the RA was used.

A left posterolateral thoracotomy was performed through the fifth intercostal space and adhesions of the collapsed left lung were dissected. After mobilisation of the left lung, the pericardium was opened above the target area, taking care with the phrenic nerve and LITA graft, which was patent in all our patients. We limited dissection of the adhesive tissues because extensive dissection may cause increased venous bleeding and a decrease in the natural stabilisation provided by the adhesions in redo $\mathrm{CABG}$ patients. ${ }^{7}$

After graft preparation, the proximal anastomosis was performed by placing a side-biting clamp on the descending aorta

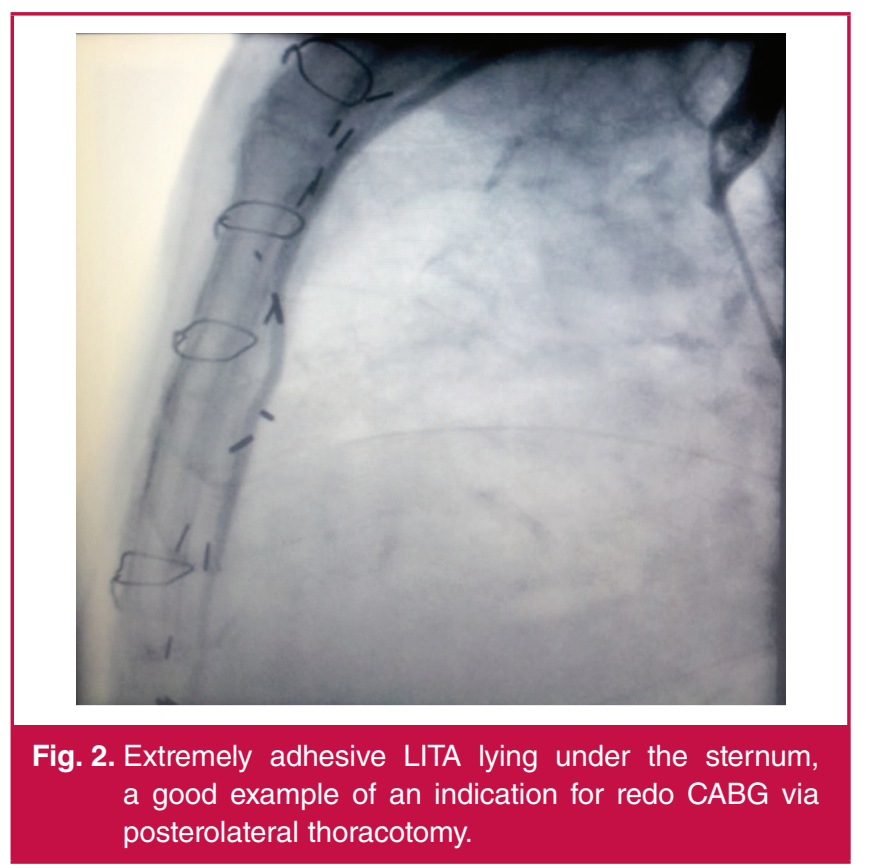




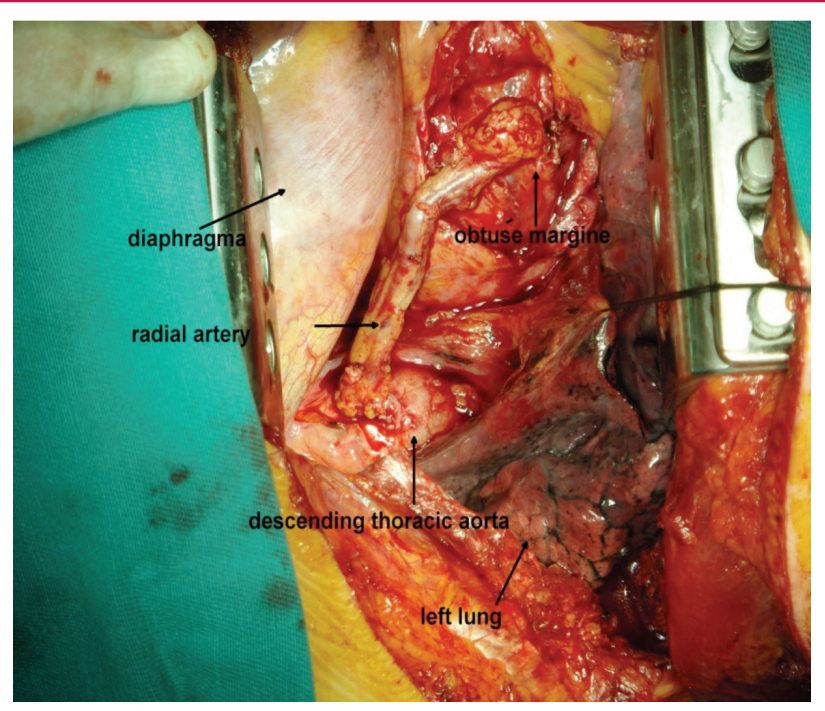

Fig. 3. Operative view of redo off-pump CABG for the obtuse marginalis branch of the $\mathrm{Cx}$ via a posterolateral thoracotomy.

in a continuous fashion with a 7-0 polypropylene suture. The descending aorta was used for the inflow in all patients. When the target vessel was identified posterolaterally, four stabilising sutures were placed at each corner. ${ }^{8}$ After arteriotomy, to achieve a comfortable distal anastomosis, a fine vascular occlusion clamp was used to stop bleeding and the distal anastomosis was performed continuously with an 8-0 polypropylene suture. The position and length of the graft was controlled meticulously to protect it from kinking (Fig. 4). ${ }^{9}$

\section{Results}

All operations were performed without $\mathrm{CPB}$ and electively via thoracotomy. None required conversion to resternotomy or

\begin{tabular}{|lcrr|}
\multicolumn{5}{c}{ Table 3. Operative findings } & & \\
Variables & Mean $(n=32)$ & Min & Max \\
Operation time (min) & $143.90 \pm 36.93$ & 90 & 270 \\
Drainage (ml) & $497.65 \pm 291.43$ & 100 & 1550 \\
Number of anastomoses & $1.1875 \pm 0.39$ & 1 & 2 \\
Respiratory assist (h) & $5.08 \pm 1.88$ & 2 & 10 \\
ICU stay (h) & $21.3 \pm 4.41$ & 14 & 36 \\
Hospital stay (days) & $5.06 \pm 2.74$ & 4 & 18 \\
Mortality & 0 & & \\
Early complications & & & \\
Myocardial infarction & 0 & & \\
Use of IABP & 0 & & \\
(+) inotrope & 1 & & \\
Atrial fibrillation & 1 & & \\
Deep-vein thrombosis & 1 & & \\
Thoracotomy incision infection & 1 & & \\
Revision for bleeding & 1 & & \\
Follow up (months) & $56.17 \pm 39.20$ & & \\
Alive and well & 22 & & \\
Lost to follow up & 6 & & \\
Dead & 4 & & \\
\hline
\end{tabular}

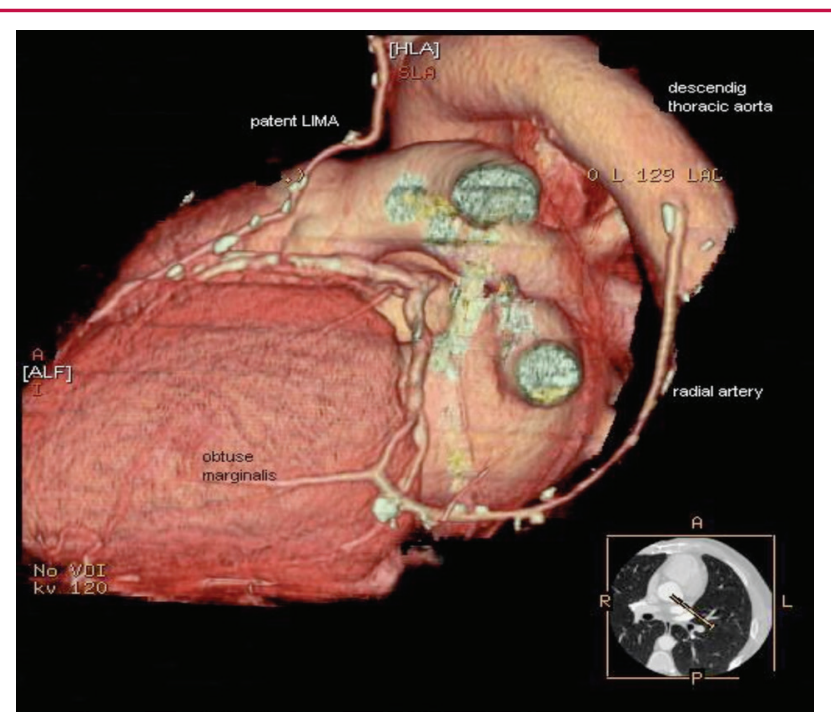

Fig. 4. The radial artery was anastomosed between the descending thoracic aorta and obtuse marginalis branch of the $\mathrm{Cx}$ without any kinking.

institution of CPB. The average surgery time was $143.90 \pm 36.93$ minutes. The number of anastamoses was $1.1875 \pm 0.39$ per patient $(38 / 32)$. Average ICU stay was $21.3 \pm 4.41$ hours with $5.08 \pm 1.88$ hours of respiratory assist, and drainage was 497.65 $\pm 291.43 \mathrm{ml}$. Average hospital stay was $5.06 \pm 2.74$ days (Table 3 ).

The follow-up period was $56.17 \pm 39.2$ months $(1-152)$ postoperatively. Twenty-two of 32 patients were alive and well, six patients were lost in the follow-up period and four patients died. There was no in-hospital mortality. All were discharged free of angina. No peri-operative myocardial infarction was observed, none of our patients required intra-aortic balloon pump (IABP) and no renal failure occurred. One patient recovered with the help of positive inotropic support. Atrial fibrillation developed in one patient, deep-vein thrombosis in another, and infection occurred in the thoracotomy incision scar of a third patient. Unfortunately one patient underwent a revision because of bleeding.

\section{Discussion}

Redo $\mathrm{CABG}$ presents challenges that initial CABG surgery does not pose. Re-operative technique and the deteriorating condition of these patients cause raised morbidity and mortality rates of re-operated patients compared with the initial CABG patients. ${ }^{6}$ The most serious complications in isolated redo CABG are massive haemorrhage, injury to patent LITA grafts, and embolisation of the patent but very atherosclerotic ascending aorta and old venous grafts due to median resternotomy and extensive dissection of the heart. ${ }^{10-12}$

Recurrent coronary artery patients who are candidates for re-operation tend to be affected more negatively by the deleterious effects of CPB because of their decreased capacity for cardiac contractility. ${ }^{6}$ Off-pump redo $\mathrm{CABG}$ revascularising the $\mathrm{Cx}$ and its branches via a left posterolateral thoracotomy in carefully selected patients presents dramatically improved consequences as a result of avoiding median resternotomy and CPB. ${ }^{5,13,14}$ 
In our clinic, selected candidates for this procedure are patients suffering from angina due to lesions in the $\mathrm{Cx}$ and its branches, who are non-responsive to medical therapy and/or with failure of PTCA/stent. All must have patent LITA-LAD anastomoses. Other indications mentioned in the literature for this procedure are: calcified ascending but not descending aorta, sternum osteomyelitis or mediastinitis, mediastinal irradiation, requirement of concomitant left lung surgery, and previous mitral valve replacement, which creates a risk for atrioventricular groove rupture while rotating the heart to approach the arteries from the lateral aspect. ${ }^{15,16}$

We believe that re-operative off-pump CABG, performed via a left posterolateral thoracotomy to revascularise the $\mathrm{Cx}$ and its branches eliminates the difficulties of median resternotomy, in addition to the potential negative effects of bleeding and embolisation due to cardiac and conduit injury during extensive dissection of the heart. Avoiding resternotomy and $\mathrm{CPB}$ in re-operative isolated $\mathrm{CABG}$ surgery decreases morbidity and mortality rates. ${ }^{4,5}$

\section{Conclusion}

In selected patients, off-pump re-operative $\mathrm{CABG}$ for the $\mathrm{Cx}$ and its branches via a left posterolateral thoracotomy can be performed with lower rates of morbidity and mortality in addition to cost-effective consequences.

This study was presented at the 23rd World Congress of the World Society of Cardiothoracic Surgeons, Split, from 12-15 September 2013.

\section{References}

1. Yap C-H, Sposato L, Akowuah A, Theodore S, Dinh DT, Shardey GC, et al. Contemporary results show repeat coronary artery bypass grafting remains a risk factor for operative mortality. Ann Thorac Surg 2009; 87: 1386-1391.

2. Subramanian S, Sabik JF 3rd, Houghtaling PL, Nowicki ER, Blackstone EH, Lytle BW. Decision-making for patients with patent left internal thoracic artery grafts to left anterior descending. Ann Thorac Surg 2009; 87(5): 1392-1398; discussion 1400.

3. Baumgartner FJ, Gheissari A, Panagiotides GP, Capouya ER, Declusin RJ, Yokoyama T. Off-pump obtuse marginal grafting with local stabilization: Thoracotomy approach in reoperations. Ann Thorac Surg 1999; 68(3): 946-948.
4. Tavilla G, Bruggemans EF. Avoiding sternotomy in repeat coronary artery bypass grafting: Feasibility, safety, and mid-term outcome of the transabdominal off-pump technique using the right gastroepiploic artery. $J$ Thorac Cardiovasc Surg 2012; 144(1): 124-129.

5. Takahashi K, Takeuchi S, Ito K, Chiyoya M, Kondo N, Minakawa M. Reoperative coronary artery bypass surgery: avoiding repeat median sternotomy. Ann Thorac Surg 2012; 94(6): 1914-9. doi: 10.1016/j.athoracsur.2012.07.007. Epub 2012 Sep 28.

6. He GW, Acuff TE, Ryan WH, He YH, Mack MJ. Determinants of operative mortality in reoperative CABG. $J$ Thorac Cardiovasc Surg 1995; 110: 971-978.

7. Azoury FM, Gillinov AM, Lytle BW, Smedira NG, Sabik JF. Off-pump reoperative coronary artery bypass grafting by thoracotomy: patient selection and operative technique. Ann Thorac Surg 2001; 71(6): 1959-1963.

8. Kurtoglu M, Ates S, Demirozü T, Duvan I, Karagoz HY, Aybek T. Facile stabilization and exposure techniques in off-pump coronary bypass surgery. Ann Thorac Surg 2008; 85(5): e30-1.

9. Ricci M, Karamanoukian HL, D’Ancona G, Salerno TA, Bergsland J. Reoperative 'off-pump' circumflex revascularization via left thoracotomy: how to prevent graft kinking. Ann Thorac Surg 2000; 70(1): 309-910.

10. Follis FM, Pett SB Jr, Miller KB, Wong RS, Temes RT, Wernly JA. Catastrophic hemorrhage on sternal reentry: still a dreaded complication? Ann Thorac Surg 1999; 68: 2215-2219.

11. Gillinov AM, Casselman FP, Lytle BW, Blackstone EH, Parsons EM, Loop FD, et al. Injury to a patent left internal thoracic artery graft at coronary reoperation. Ann Thorac Surg 1999; 67: 382- 386.

12. Park CB, Suri RM, Burkhart HM, Greason KL, Dearani JA, Schaff $\mathrm{HV}$, et al. Identifying patients at particular risks on injury during repeat sternotomy: analysis of 2555 cardiac reoperations. $J$ Thorac Cardiovasc Surg 2010; 140: 1028-1035.

13. D'Ancona G, Karamanoukian H, Lajos T, Ricci M, Bergsland J, Salerno T. Posterior thoracotomy for reoperative coronary artery bypass grafting without cardiopulmonary bypass: perioperative results. Heart Surg Forum 2000; 3(1): 18-22; discussion 22-23.

14. Duarte CS, Moraes Neto FR, Moraes CR. Left thoracotomy for reoperations in myocardium revascularization. Rev Bras Cir Cardiovasc 2007; 22(3): 341-345.

15. Ungerleider RM, Mills NL, Wechsler AS. Left thoracotomy for reoperative coronary artery bypass procedures. Ann Thorac Surg 1985; 40(1): $11-15$.

16. Pratt JW, Williams TE, Michler RE, Brown DA. Current indications for left thoracotomy in coronary revascularization and valvular procedures. Ann Thorac Surg 2000; 70(4): 1366-1370. 